\title{
Electrochemical production,
}

characterization, and application of MWCNTs

\section{Aleksandar T. Dimitrov, Ana Tomova, Anita Grozdanov, Orce Popovski \& Perica Paunović}

\section{Journal of Solid State}

Electrochemistry

Current Research and Development in Science and Technology

ISSN 1432-8488

Volume 17

Number 2

J Solid State Electrochem (2013) 17:399-407

DOI 10.1007/s10008-012-1896-z

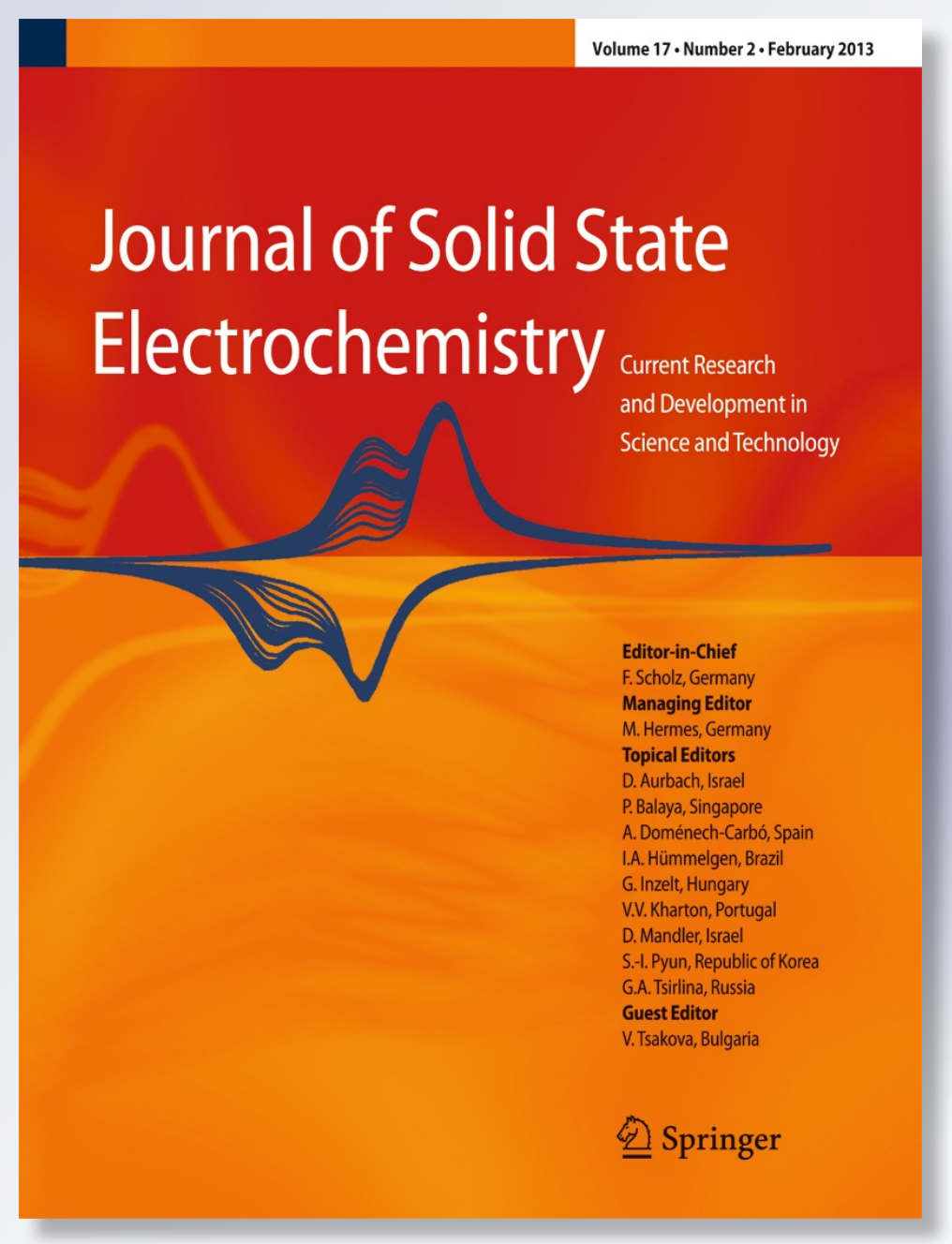

望 Springer 
Your article is protected by copyright and all rights are held exclusively by SpringerVerlag Berlin Heidelberg. This e-offprint is for personal use only and shall not be selfarchived in electronic repositories. If you wish to self-archive your work, please use the accepted author's version for posting to your own website or your institution's repository. You may further deposit the accepted author's version on a funder's repository at a funder's request, provided it is not made publicly available until 12 months after publication. 


\title{
Electrochemical production, characterization, and application of MWCNTs
}

\author{
Aleksandar T. Dimitrov • Ana Tomova - Anita Grozdanov • \\ Orce Popovski • Perica Paunović
}

Received: 3 September 2012 /Revised: 26 September 2012 / Accepted: 27 September 2012 /Published online: 13 October 2012

(C) Springer-Verlag Berlin Heidelberg 2012

\begin{abstract}
The subject of this study is production of carbon nanotubes (CNTs) using an original procedure of reduction of lithium molten salts onto graphite cathode; their structural characterization and application as support material for electrocatalysts aimed for hydrogen evolution. As-produced CNTs were characterized by means of scanning and transmission electron microscopy (SEM and TEM), Raman spectroscopy, and thermogravimetric and differential thermal analysis (DTA). SEM and TEM images have shown that nanotubes are mostly of curved shape with length of $1-$ $20 \mu \mathrm{m}$ and diameter of $20-40 \mathrm{~nm}$. Raman peaks indicate that the crystallinity of produced nanotubes is rather low. The obtained results suggest that formed product contains up to $80 \%$ multiwalled carbon nanotubes (MWCNTs), while the rest being non-reacted graphite and fullerenes. DTA curves show that combustion process of the nanotubes takes place in two stages, i.e., at 450 and $720{ }^{\circ} \mathrm{C}$. At the lower temperature, combustion of MWCNTs occurs, while at higher one, fullerenes and non-reacted graphite particles burn. As-produced MWCNTs were used as electrocatalyst's support materials and their performance was compared with that of traditional carbon support material Vulcan XC-72. MWNTs have shown almost twice higher real surface area, and electrocatalyst deposited on them showed better catalytic activity than corresponding one deposited on Vulcan XC-72.
\end{abstract}

\footnotetext{
A. T. Dimitrov $\cdot$ A. Tomova $\cdot$ A. Grozdanov $\cdot$ P. Paunović $(\triangle)$ Faculty of T echnology and Metallurgy, University "St. Cyril\&Methodius", Skopje, Rudjer Boskovic 16, Skopje 1000, Republic of Macedonia e-mail: pericap@tmf.ukim.edu.mk

O. Popovski

Military Academy "Mihailo Apostolski", Skopje,

Vasko Karangeleski str., b.b.,

Skopje 1000, Republic of Macedonia
}

Keywords Multiwalled carbon nanotubes (MWCNTs) . Intercalation · Graphite $\cdot$ Molten salts electrolysis · Support material $\cdot$ Hydrogen evolution

\section{Introduction}

Carbon nanotubes (CNTs), discovered by Iijima [1], are supposed to be a key component of many technologies because of their outstanding structural, mechanical, and electronic properties. They are microscale length graphene tubes with end "caps" consisted either of one graphitic layer and 1-2 $\mathrm{nm}$ in diameter (single walled nanotubes, SWCNTs) or of two or more graphitic layers, with interlayer spacing of $0.34 \mathrm{~nm}$ and diameters of 2-20 nm (multiwalled carbon nanotubes, MWCNTs).

As result of their pronounced electrical, mechanical, and chemical properties, almost every week a new potential application of CNTs is identified in a wide range of modern science and engineering. They have variety of applications in analytical chemistry such as design of novel gas sensors, voltammetry, enzymatic biosensors, DNA probes, scanning probes, etc. $[2,3]$. Their conductivity and small size impose them as key material in molecular electronics and electronic devices $[4,5]$ Furthermore, CNTs have a great potential to be used as fillers in polymer composites replacing carbon fibers and carbon blacks [6]. Several applications for CNTs have been suggested in energy production and energy storage devices as an electrode material in lithium ion batteries and or in electrochemical capacitors [7-9].

CNTs can be produced by various methods. There are three predominant methods for their synthesis: electric arc discharge [10], laser ablation of carbon target [11], and chemical vapor deposition [12]. But, generally, these 
production procedures are rather expensive and not very productive. The large-scale use of CNTs is still limited due to the high production costs and the low productivity. The use of CNTs requires a production method that combines growth control with low costs and scalability.

Hsu and coworkers have developed a new electrolytic method, very promising for producing carbon nanotubes $[13,14]$. The essence of this method is electrowinning of alkali metals ( $\mathrm{Li}, \mathrm{Na}$, and $\mathrm{K}$ ) or alkali earth metals $(\mathrm{Mg}, \mathrm{Ca})$ from their molten chloride salts on a graphite cathode, followed by formation of CNTs by the interaction of deposited metal with the cathode. They electrolyzed molten lithium chloride using graphite electrodes. The cathode eroded during the electrolysis and nanoscale products, including MWCNTs, were found in the electrolyte.

Electrolytic production of carbon nanotubes in chloride oxide melts under carbon dioxide pressure was studied by Novoselova et al. [15]. The electrochemical study of peculiarities of carbon solid phase deposition from halide melts $(\mathrm{NaCl}: \mathrm{KCl})$ saturated by carbon dioxide under excessive pressure up to $1.5 \mathrm{MPa}$ was carried out in the range of 500 to $800{ }^{\circ} \mathrm{C}$ by the method of cyclic voltammetry. They have characterized the chemical, phase, and structural composition of the obtained cathode products. It was found that cathode deposits contain carbon nano-sized particles of different forms and structure: blocks of amorphous carbon, crystalline graphite, carbon nanotubes, and nanofibers.

Chen et al. $[16,17]$ have connected the erosion of the cathode and the formation of the products to the intercalation of alkali metals into graphite. This was extended further by Fray $[18,19]$ who pointed out that the cathodic carbon/ graphite erosion is similar to that found in the Hall-Heroult cell where alkali metals also intercalate into graphite.

Dimitrov et al. $[20,21]$ reported that the constant voltage molten salt electrolysis, as opposed to the constant current electrolysis that had been applied in most previous cases, could improve and increase the yield of produced CNTs. This method is considered as a more advantageous and economical method when compared with arc discharge, CVD, and laser ablation methods due to the lower cost of energy, the setup simplicity required, and the large-scale production of CNTs. Also, the present authors have applied chronoamperometric method [22], where the results confirmed that EC4 is a proper material for the present purpose. The idea of this method was avoiding cathode blocking, electrode cracking caused by current peaks, and improvement of CNTs production. Furthermore, comparison with the data obtained with previous used methods and assessed the influence of electrode polarity switching time, the cathode exfoliation, and production of CNTs [22].

In recent time, one of the ways to improve electrocatalytic activity of the electrode materials aimed for water electrolysis/fuel cells as well as to reduce the amount of $\mathrm{Pt}$ is using carbon nanotubes as support material. Actually, the most used support material for the above-mentioned purpose is carbon black-Vulcan XC-72. Its distinctive properties such as high degree of ordering, appropriate physical and chemical surface characteristics, and high electron conductivity are decisive for that [23]. But, the unique physical properties of CNTs such as electroconductivity, mechanical stability, surface area, porosity, etc. make them very attractive as support material for electrocatalysts in hydrogen economy. In comparison with Vulcan XC-72, CNTs have considerably higher electronic conductivity of $10^{4} \mathrm{Scm}^{-1}$ [24], while specific surface area is in range of 200-900 $\mathrm{m}^{2}$ $\mathrm{g}^{-1}$ [24]. Also, Vulcan XC-72 has micropores smaller than $2 \mathrm{~nm}$, while this is not case with CNTs [25]. This is important for electrocatalytic behavior because small nanostructured metallic phase can sink into the micropore, reducing the three-boundary reaction sites. Other advantage of CNTs vs. Vulcan XC-72 is higher chemical, i.e., corrosion stability. This is a very important parameter for anodic reactions oxygen evolution in hydrogen electrolysers and hydrogen oxidation in fuel cells. Namely, electrochemical degradation of carbon materials is slowed considerably by carbon graphitization [23].

The aims of this work include synthesis of CNTs using electrolysis in molten $\mathrm{LiCl}$; their characterization by means of scanning electron microscopy (SEM), transmission electron microscopy (TEM), thermogravimetric analysis (TGA), and Raman spectroscopy; as well as their application as support material for non-platinum electrocatalysts aimed for hydrogen evolution reaction.

\section{Experimental}

MWCNT's were produced in alumina crucible with a volume of $150 \mathrm{~cm}^{3}$, as the container of the molten salt electrolyte. The commercial graphite rods, type EC4, with average grain size of $0.038 \mathrm{~mm}$ and density of $1.75 \mathrm{gcm}^{-3}$ and $6.5 \mathrm{~mm}$ in length were used as both an anode and cathode material [21]. As an electrolyte, molten $\mathrm{LiCl}$ was used. The cell was placed inside a sealable Inconel tube reactor with water-cooled jacket and heated by a vertical Lenton furnace equipped with a programmable controller. The salt was always thermally pre-dried in an argon atmosphere inside the Inconel tube at $250{ }^{\circ} \mathrm{C}$ for at least $2 \mathrm{~h}$ and further melted in an argon atmosphere. The electrolysis was controlled by a Farnell LS30-10 auto ranging power supply. After the each experiment, the cathode was removed and the electrolyte was left to solidify overnight. Typically, the solidified salt was then dissolved in distilled water with the aid of mechanic stirring and left for the solvents to phase separate.

The carbonaceous phases extracted from the solidified electrolyte were observed by scanning and transmission 
Fig. 1 SEM images of CNTs produced by electrolysis in molten LiCl. Magnification: a $\times 10,000 ; \mathbf{b} \times 20,000$; c $\times 40,000$; and $\mathbf{d} \times 150,000$
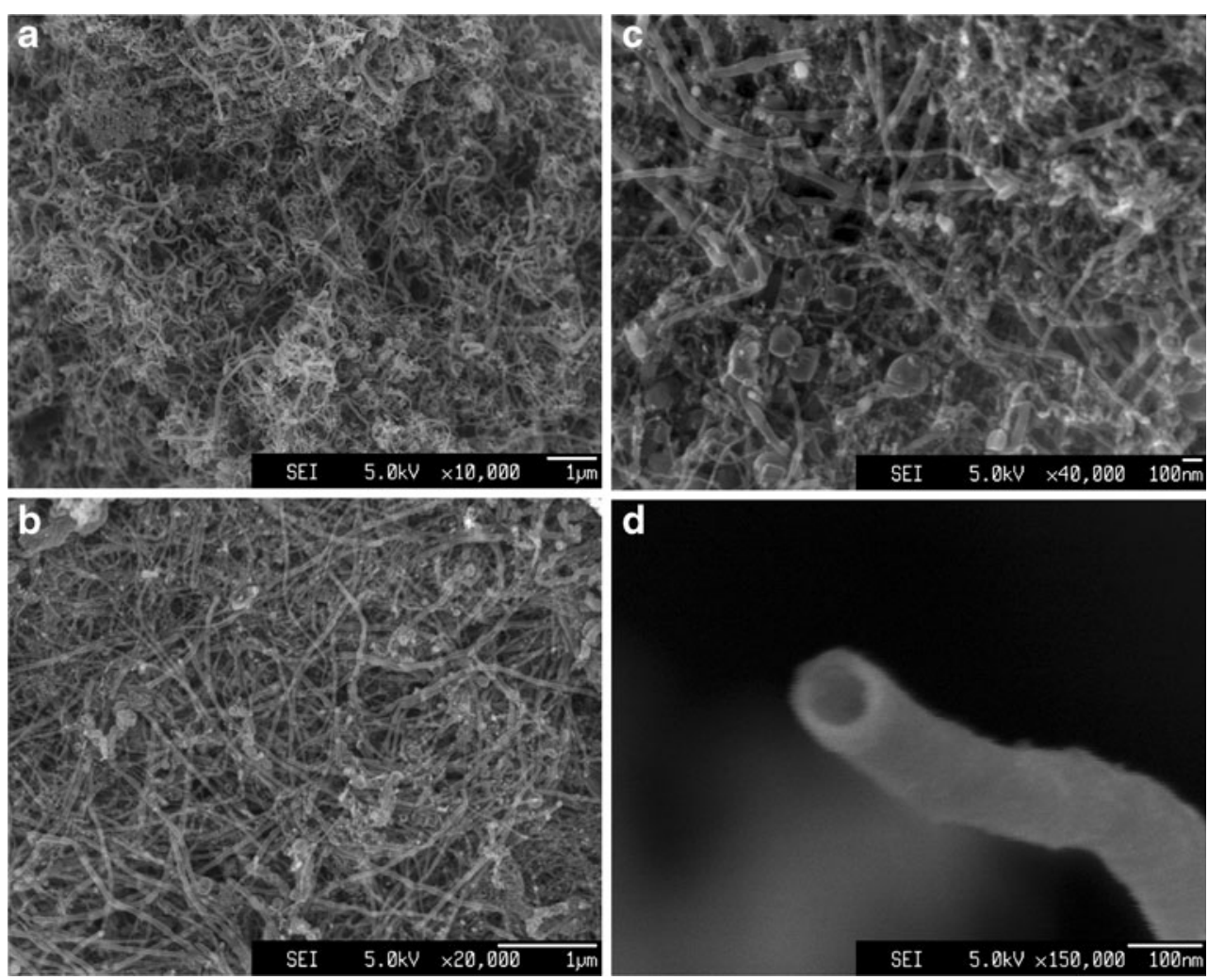

electron microscopy, using JEOL 6340F (SEM, $10 \mathrm{kV}$ ) and JEOL 200CX (TEM, $200 \mathrm{kV}$ ). The thermal stability of the carbonaceous product was measured using TGA/differential thermal analysis (DTA) using Perkin Elmer thermogravimetric/differential thermal analyzer in temperature range of
0 to $1,200{ }^{\circ} \mathrm{C}$ with heating rate of $10{ }^{\circ} \mathrm{Cmin}^{-1}$. Structural characteristics were studied by means of Raman spectroscopy (Renishaw Ramascope 1000).

The ratio of real versus geometric surface area $\left(S_{\mathrm{R}} / S_{\mathrm{G}}\right)$ of the produced carbon nanotubes was determined by
Fig. 2 TEM images of CNTs produced by electrolysis in molten $\mathrm{LiCl}$
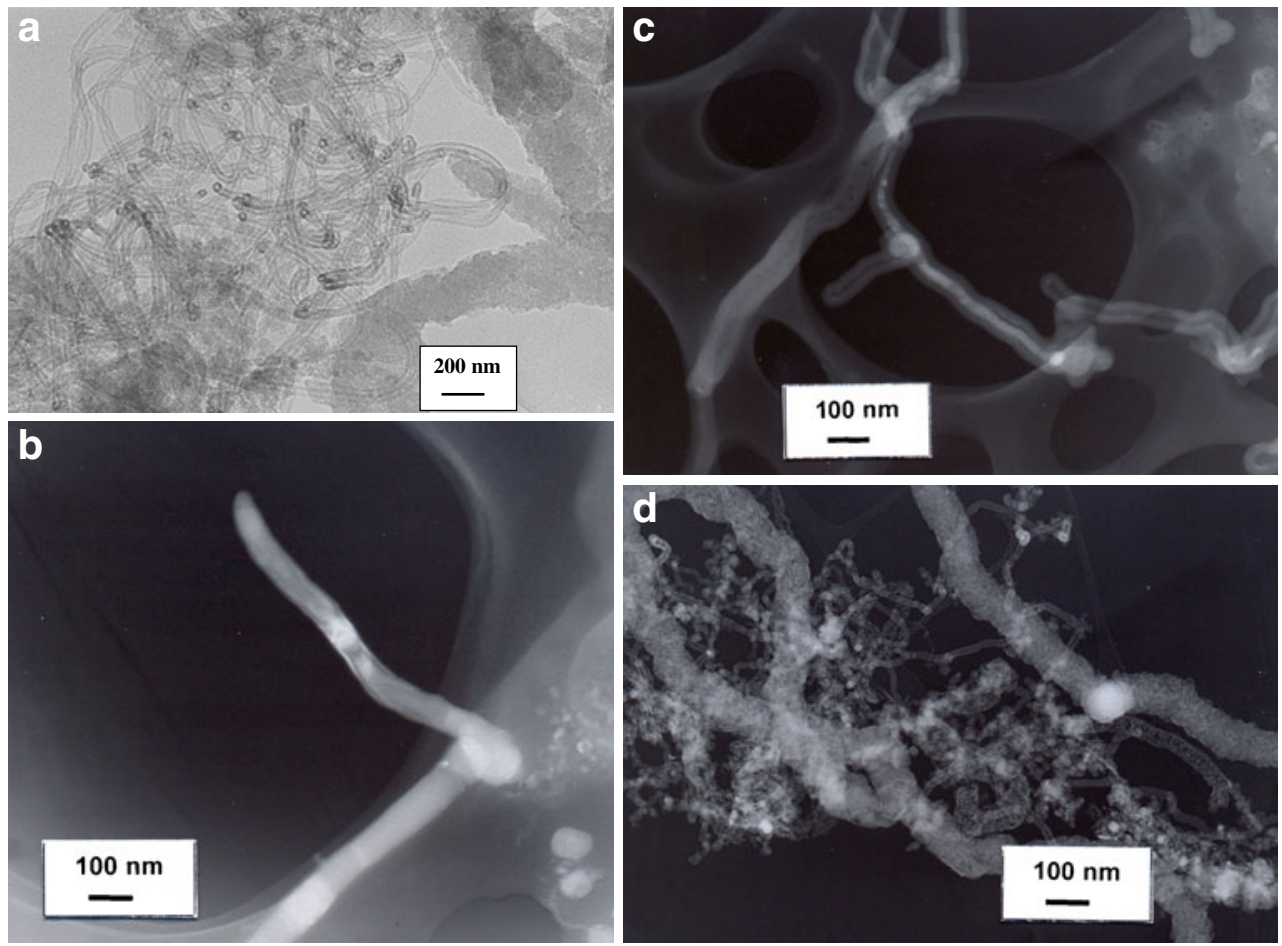
measuring the double layer capacity using cyclic voltammetry $[26,27]$. For comparison, the same measurements were performed for Vulcan XC-72. Cyclic voltammetry (CV) measurements were performed in alkaline solution (3.5 $\mathrm{M} \mathrm{KOH})$ in the region of potentials where only charging of double layer occurs with scanning rate of 1 to $10 \mathrm{mVs}^{-1}$. Electrochemical AMEL equipment (Function Generator AMEL 568, Potentiostate/Galvanostate 2053 and software package SOFTASSIST 2.0) was used. Gas diffusion electrodes were prepared out of the produced carbonaceous powder by hot pressing at $300{ }^{\circ} \mathrm{C}$ with the back layer of carbon black acetylene + PTFE and the front layer of the CNTs + PTFE. The counter electrode was a platinum wire, the reference one- $\mathrm{Hg} / \mathrm{HgO}$, while the electrolyte was a solution of $3.5 \mathrm{M} \mathrm{KOH}$ (p.a., Merck) in deionizated ultrapurified water.
Electrocatalysts were prepared by sol-gel procedure described elsewhere [28]. They consist of $10 \mathrm{wt} \%$ hyper-dmetallic phase (CoNi), 18 wt $\%$ hypo-d-oxide phase $\mathrm{TiO}_{2}$ deposited on carbon substrate-as-produced MWCNTs or Vulcan XC-72 for comparison. As precursors of catalyst's components, organometallics were used (Me 2,4-pentanedionat, $\mathrm{Me}\left(\mathrm{CH}_{3} \mathrm{COCHCOCH}_{3}\right)_{2}(\mathrm{Me}=\mathrm{Co}$ and $\mathrm{Ni})$, Alfa Aesar, Johnson Matthey, $\mathrm{GmbH}$ and Ti-isopropoxide, $\mathrm{Ti}\left[\mathrm{OCH}\left(\mathrm{CH}_{3}\right)_{2}\right]_{4}$, Aldrich, $\left.97 \%\right)$. As a referent electrocatalysts, traditional Pt deposited on Vulcan XC-72 was prepared by the same procedure.

The structure of hypo-hyper-d-electrocatalysts was observed by SEM, JEOL, model JEM CX. The ratio of real versus geometric surface area $\left(S_{\mathrm{R}} / S_{\mathrm{G}}\right)$ of the electrocatalysts deposited on MWCNTs and Vulcan XC-72 were determined
Fig. 3 Thermogravimetric analysis of a carbon nanotubes samples obtained by electrolysis in molten salt and $\mathbf{b}$ graphite samples used as a cathode. Blue line TGA curves, green line DTA curves a

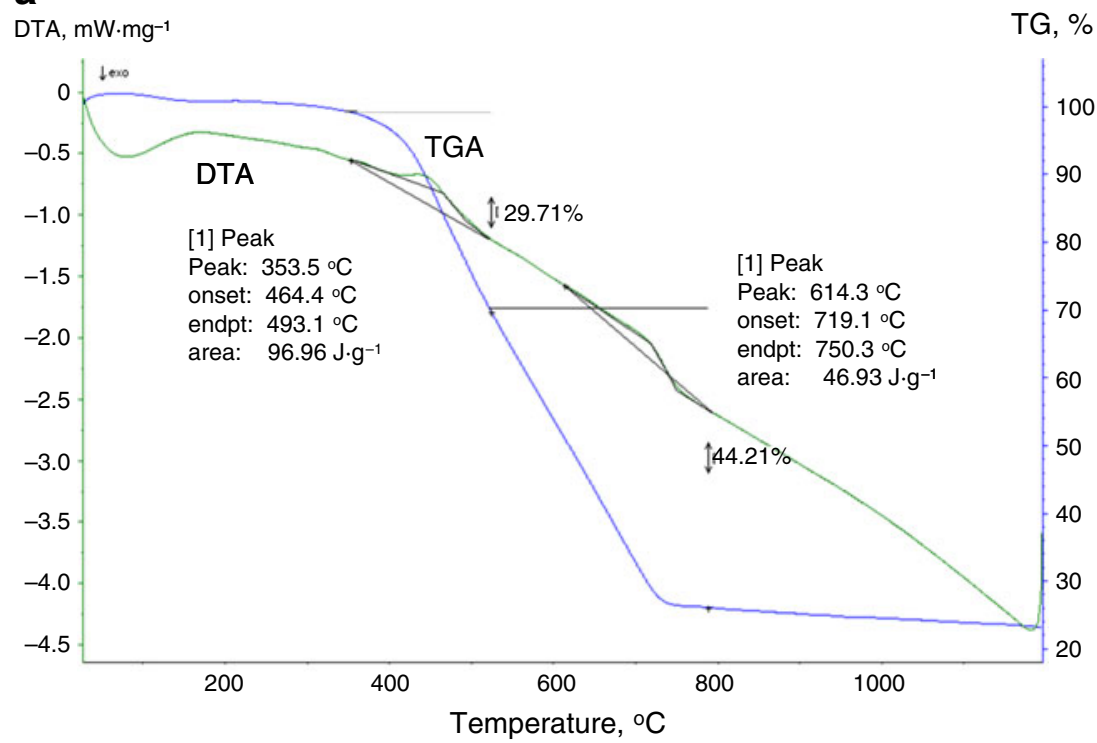

b

DTA, mW.mg-1

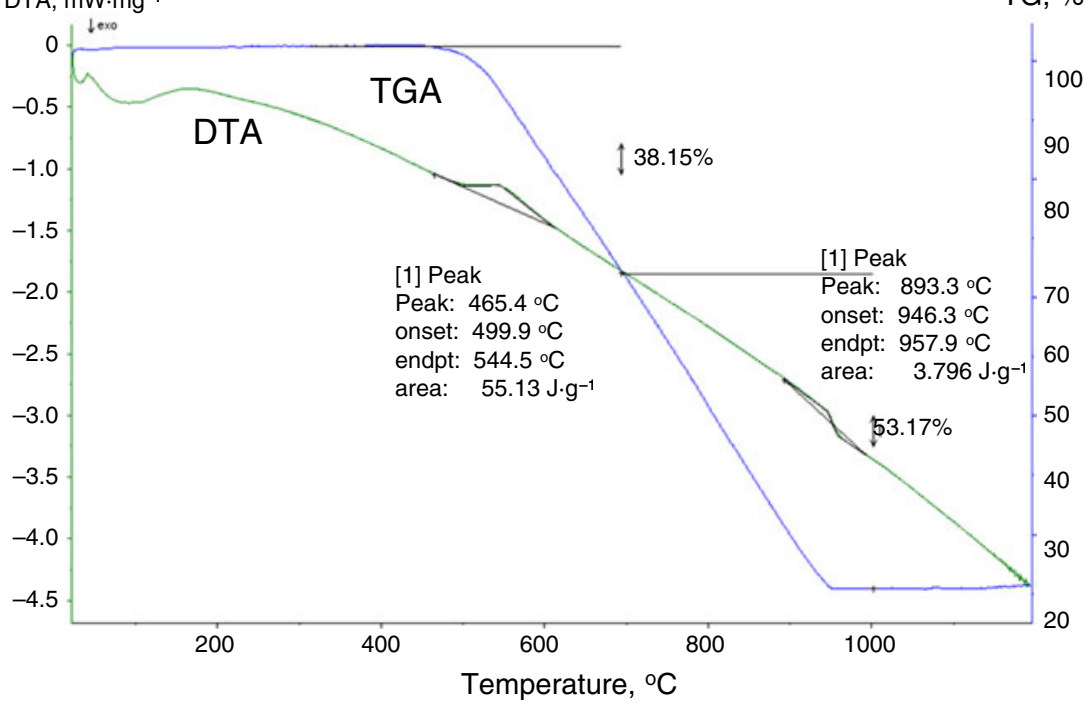


by the same procedure mentioned above. Electrochemical characterization, i.e., electrocatalytic activities of the studied electrocatalysts, was studied by means of cyclic voltammetry and steady-state galvanostatic method. The same instrumentation explained above was used. During the electrochemical testing, the solution in the cathodic area was purged by hydrogen.

\section{Results and discussion}

In the recent papers of the present author [20,21], it was reported that the constant voltage electrolysis, as opposed to the constant current (galvanostatic) electrolysis, could improve and increase the yield of produced CNTs. Thus, the goal of this study was (1) to improve the process of MWCNTs production by electrolysis in molten lithium chloride by passing an electric current through a molten ionic salt between graphite electrodes at a constant overpotential, (2) to carry out physical characterization of carbon nanotubes produced by this method, and (3) to apply the produced carbon nanotubes as a catalyst support for electrocatalysts aimed for hydrogen evolution.

Physical characterization of the produced carbon nanotubes

Electron microscopy was used mainly to identify and evaluate different constituents in the carbonaceous products and contribution of the CNTs in them. SEM images of the CNTs obtained by electrolysis at a constant overpotential are shown in Fig. 1, with the low and high magnification, respectively. Generally, the obtained carbonaceous products surprisingly contain a large quantity of MWCNTs, more than $80 \%$. In comparison with our previous results [21], the results presented in this study show that the yield of carbon nanotubes is more than three times higher. The morphology of the products obtained by electrolysis in molten $\mathrm{LiCl}$ is very similar to those reported previously $[16,21]$. The size of the produced carbon nanotubes is ranged between 10 and $100 \mu \mathrm{m}$ in length and $20-60 \mathrm{~nm}$ in diameter.

As we could see, the nanotubes are highly entwined similar to the nanotubes produced catalytically using a floating catalysts. Also, SEM and TEM observations show that the nanotubes could extend between two separate aggregates and end up in each. But, normally, most of them start and end in the same aggregate with some exception curving out of the aggregate.

In addition to nanotubes, the other constituent in the product were observed, such as some aggregated carbon nanoparticles and some small pieces of unreacted graphite particles (Fig. 1c).

TEM images in Fig. 2 also show CNTs produced under the same conditions. The material was found to be aggregated in the aggregates consisted of nanotubes and nanoparticles. TEM observation shows that some of these tubes and particles contain a foreign material. These filings could be either lithium or lithium carbide, if it is formed. The images also show that most of the material, $>80 \%$, are MWCNTs. There are small amount of impurities, as metal particles, carbon fibers, amorphous carbon structures, and impurities originating from the salt.

SWCNTs were not found in the material produced and inspected during this study. This fact may lead to the conclusion that under those circumstances, production of SWCNTs is not possible.

Analysis of the thermal stability of the carbon nanotubes is an appropriate method for determination of the overall quality of the obtained carbon nanotubes. Thermogravimetric analysis includes heating the produced carbonaceous
Fig. 4 Normalized Raman spectra taken from MWCNTs produced by electrolyses in molten $\mathrm{LiCl}$

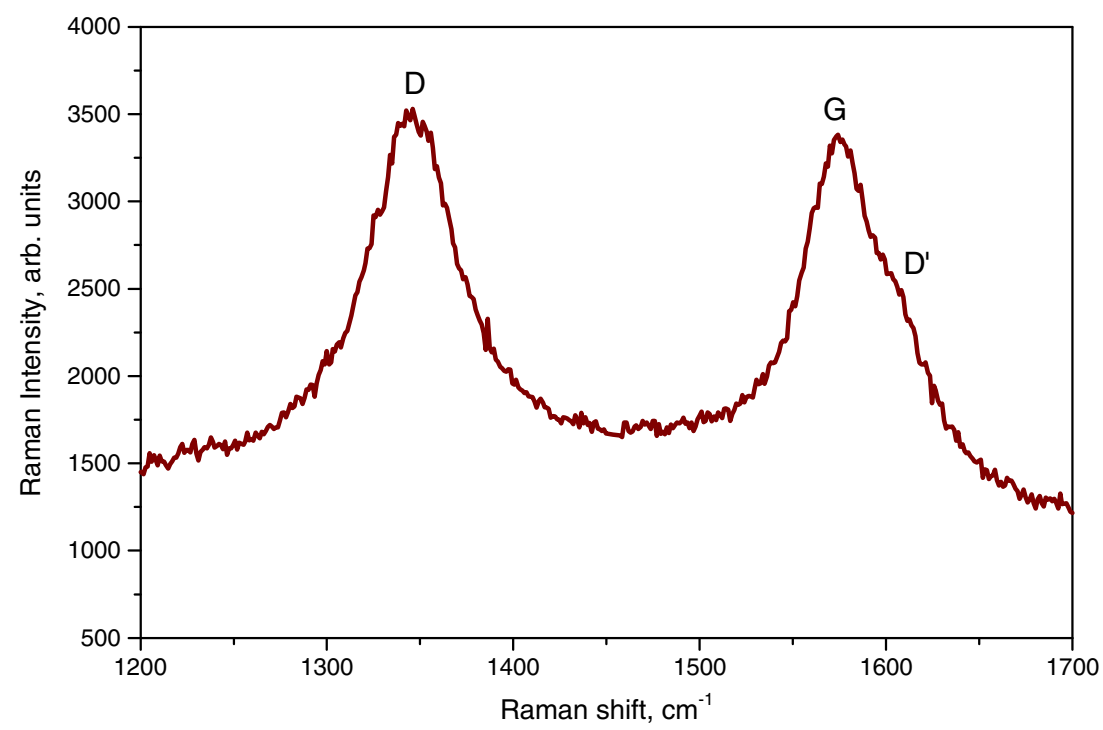


material by electrolysis in molten salt under oxygen flow, whereat the various components oxidize at different temperatures. TGA-DTA thermograms are presented in Fig. 3, where the blue lines show the weight loss as a function of temperature from 0 to $1,200{ }^{\circ} \mathrm{C}$ and green lines are the corresponding DTA curves. TGA curve for CNTs produced by electrolysis in molten salt (Fig. 3a) shows a higher slope than that of the CNTs produced by using commercial graphite as a cathode (Fig. 3b). According the literature, this indicates a less of weight change with respect to temperature.

We will turn more attention on DTA curves because they directly reflect variation in the weight with temperature. The DTA curve obtained when commercial graphite EC4 was heated under the oxygen flow shows two peaks at about 500 and $950{ }^{\circ} \mathrm{C}$ indicating that the oxidation process of the graphite consists of two stages. However, the corresponding DTA curve for produced carbon nanotubes sample shows that the process of thermal oxidation occurs also at two stages, the first one bellow $464{ }^{\circ} \mathrm{C}$ and the second one at $719{ }^{\circ} \mathrm{C}$ (Fig. 3a). The curve indicates that probably MWCNTs oxidize at the temperature below $464{ }^{\circ} \mathrm{C}$ because the first peak can be attributed to the oxidation of the amorphous carbon, and the second peak at $719{ }^{\circ} \mathrm{C}$ corresponding to the temperature of oxidation of carbon fullerenes and unreacted graphite particles. Lower oxidation temperatures registered for the obtained MWCNT (around $400{ }^{\circ} \mathrm{C}$ ) indicate that some defects and derivatization moieties are present in the nanotubes walls that can cause the lower thermal stability. Also, less thermal stability suggests that the produced carbon nanotubes samples have smaller diameters. A smaller diameter implies a high degree of curvature which means increased contact with the air and subsequently a higher reactivity toward oxygen. This was observed also for $\mathrm{C}_{60}$ [29]. The thermogravimetric study performed by Bom and coworkers [30] has shown that graphite has a higher thermal stability than MWCNTs and oxidized at higher temperatures. We could say that our results are in contradiction with the result obtained by Bom. It is obvious that row graphite material EC4, used as an electrode material, oxidizes at temperatures which do not correspond to any of two burning temperatures of carbon nanotubes sample.

Raman spectroscopy has been used to determine crystallinity of the produced carbon materials. Shown in Fig. 4 is

Table 1 Double layer capacity, $C_{\mathrm{dl}}$, of studied materials

\begin{tabular}{ll}
\hline Sample & $C_{\mathrm{d} 1}, \mathrm{mFcm}^{-2}$ \\
\hline MWCNTs & 342 \\
Vulcan XC-72 & 179 \\
$\mathrm{CoNi}_{\mathrm{TiO}}$ /MWCNTs & 303 \\
$\mathrm{CoNi}_{\mathrm{TiO}} /$ /Vulcan & 156 \\
$\mathrm{XC}-72$ & \\
\hline
\end{tabular}

Raman spectrum of the studied material. The spectrum consists of two pronounced peaks characteristic for carbonaceous materials: $\mathrm{D}$ peak at position near $1,345 \mathrm{~cm}^{-1}$ as a result of disorders in the crystals and $G$ peak near $1,575 \mathrm{~cm}^{-1}$ as a result of in-plane vibration of the $\mathrm{C}-\mathrm{C}$ bonds. The pick $\mathrm{D}$ indicates disordered carbon atoms referred to defects as pentagons and heptagons in graphite, edges of the graphite crystal, and amorphous carbonaceous products $[31,32]$. The peak $G$ is related to the highly
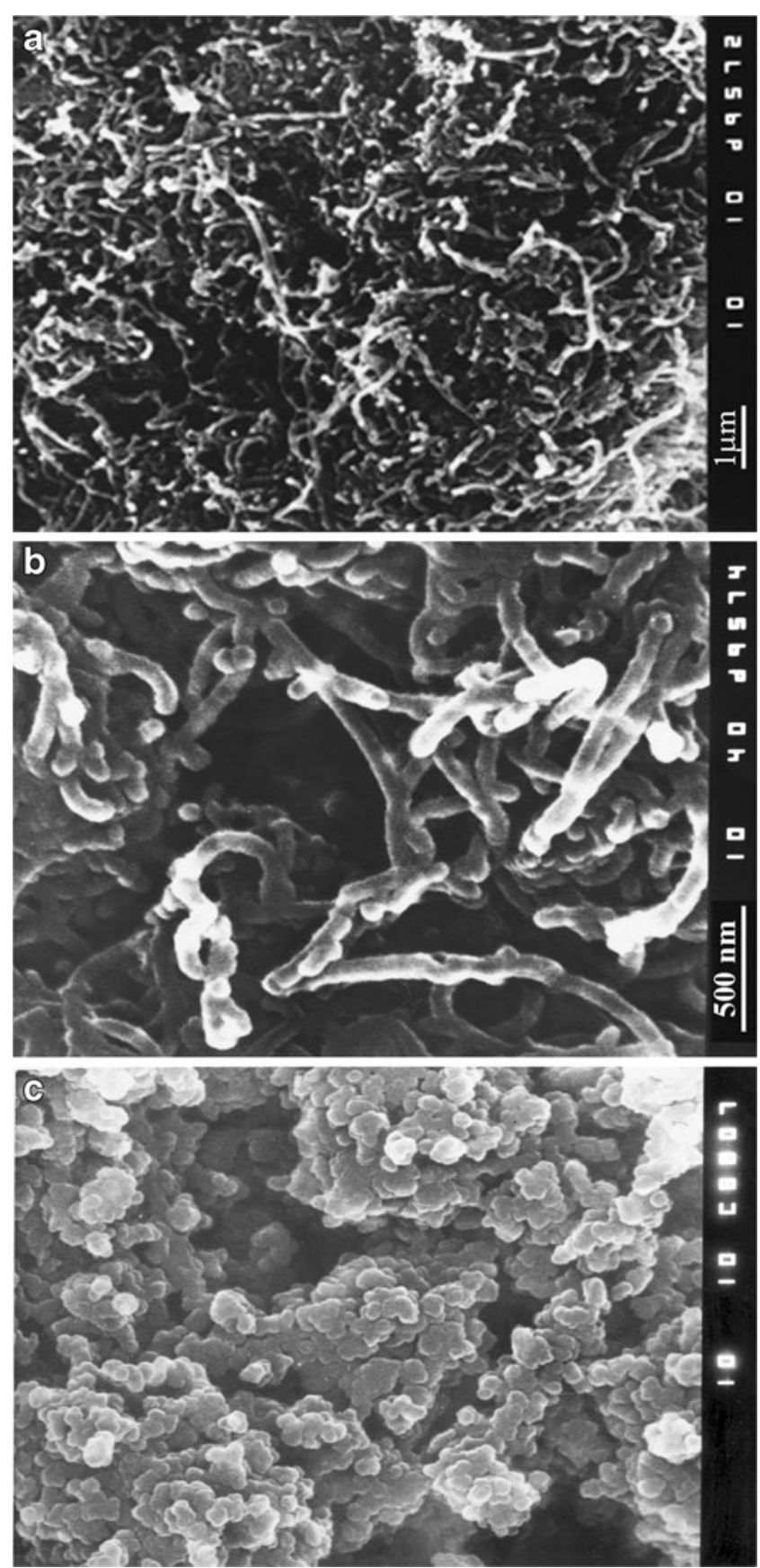

Fig. 5 SEM images of $\mathrm{CoNi} / \mathrm{TiO}_{2}$ electrocatalysts deposited on: a MWCNTs $(\times 10,000)$; b MWCNTs $(\times 40,000)$; c Vulcan XC-72 
Fig. 6 Cyclic voltammograms of the studied electrocatalysts scanned in $3.5 \mathrm{M} \mathrm{KOH}$ with scan rate of $5 \mathrm{mV} \mathrm{s}^{-1}$

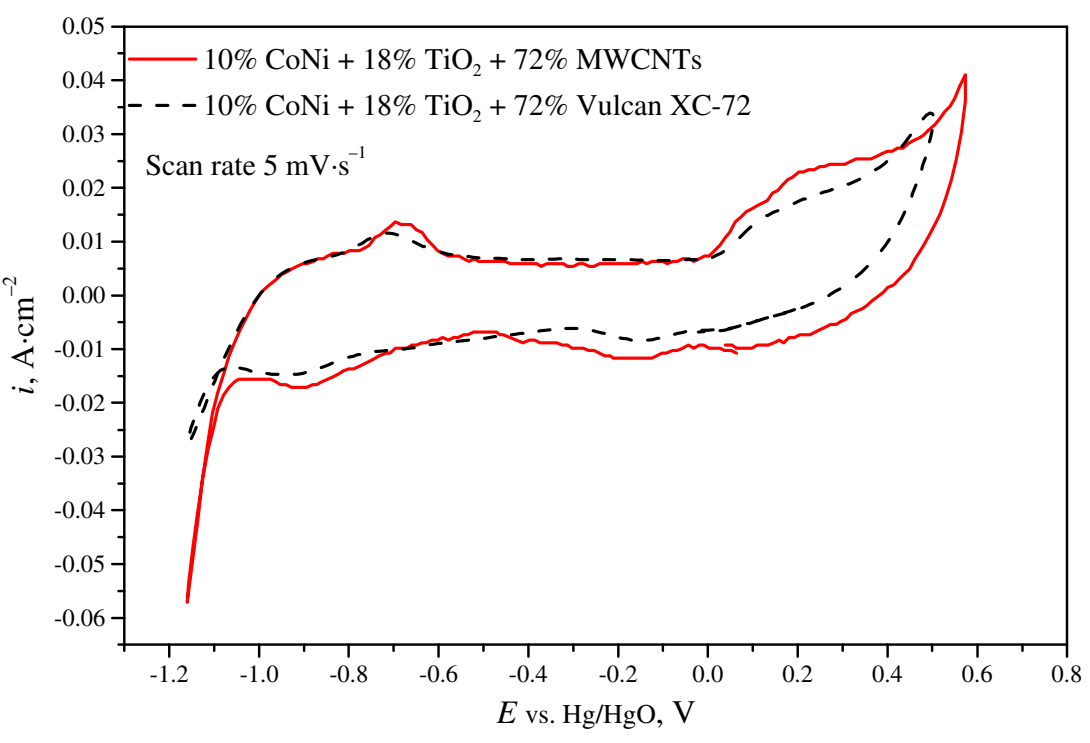

oriented graphite [33], i.e., formation of well-graphitized carbon nanotubes. On the right side of G-line, a no well pronounced shoulder peak appears at the position of near $1,610 \mathrm{~cm}^{-1}$ and denotes as $\mathrm{D}^{\prime}$ peak. The appearance of $\mathrm{D}^{\prime}$ peak points out that these carbon nanotubes are multiwalled [34]. Comparing the intensity or surface area of below D and $G$ peaks, the extent crystallinity of the material can be assessed. The ratio of intensities of the $\mathrm{D}$ and $\mathrm{G}$ maximums $\left(I_{\mathrm{D}}\right.$ and $I_{\mathrm{G}}$ ) gives an indication of the crystallinity of the studied material. The lower value of $I_{\mathrm{D}} / I_{\mathrm{G}}$ points out on higher crystallinity, while the higher ratio suggests on the higher disorder within the crystalline structure $[35,36]$. Highly oriented pyrolytic graphite (HOPG) has an $I_{\mathrm{D}} / I_{\mathrm{G}}$ ratio approaching 0 , while amorphous carbon has a value near 3.3. HOPG is a high quality graphitic material consisting of planes of carbon atoms, which are highly oriented between each other.

The ratio of intensities of the characteristic peaks $\left(I_{\mathrm{D}} / I_{\mathrm{G}}=\right.$ 1.05) for the studied MWCNTs indicates the extent of defects and impurities in the produced material. The Raman spectrum as well as the TEM and SEM analysis confirmed that there were no single-walled nanotubes present in the sample.

Application of the produced MWCNTs as electrocatalyst's support materials

To determine the ratio of real vs. geometrical surface area, $S_{\mathrm{R}} / S_{\mathrm{G}}$, the double layer capacity $\left(C_{\mathrm{dl}}\right)$ of the produced carbon nanotubes and catalysts deposited on carbon nanotubes was measured by $\mathrm{CV}$. For comparison, corresponding measurements were performed on pure Vulcan XC-72 and corresponding electrocatalyst deposited on Vulcan XC-72. $\mathrm{CV}$ scanning was performed in the region of potentials where only charging of double layer occurs with scanning rate from 1 to $10 \mathrm{mV} \mathrm{s}^{-1}$. The procedure for determination of $C_{\mathrm{dl}}$ electrocatalysts deposited on these carbon substrates is presented elsewhere [37]. The values for the double layer capacity for the manufactured and purified MWCNTs are shown in Table 1. The produced carbon nanotubes have shown considerable higher value for the double layer capacity, almost twice. This means that they have almost twice higher developed surface area. Also, similar ratio was observed for corresponding $\mathrm{CoNo} / \mathrm{TiO}_{2}$ electrocatalysts deposited on MWCNTs and Vulcan XC-72.

In Fig. 5, SEM images of the $\mathrm{CoNo} / \mathrm{TiO}_{2}$ electrocatalysts deposited on both MWCNTs and Vulcan XC-72 are shown. According to SEM images, electrocatalyst deposited on MWCNTs has intertwined thread-like morphology, as a result of the presence of the MWCNTs (Fig. 5a, b). This morphology is more appropriate than that of electrocatalyst deposited on Vulcan XC-72 which shows spherical shape and larger size of particles (Fig. 5c). In case of catalyst

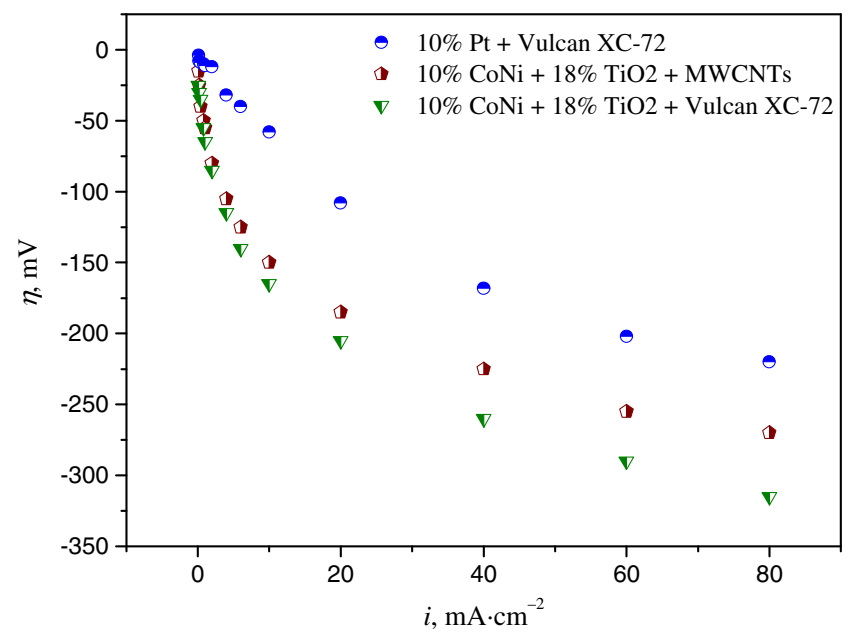

Fig. 7 Polarization curves of the studied electrocatalysts 
deposited on MWCNTs, catalyst's components are grouped into smaller clusters. Also, there are more holes between them which lead to better inter-particle porosity of the catalyst. Due to the intrinsic geometric shape of MWCNTs (empty cylinders ordered one over the other), they possess inner holes, so the inner or trans-particle porosity of electrocatalysts deposited on MWCNTs is considerably higher.

In Fig. 6, cyclic voltammograms of the CoNi electrocatalysts deposited on both carbon support materials are shown. In both, voltammograms can be seen with characteristic peaks for transition of Co to higher valence states [37,38]. Also, it can be seen that surface and electrode processes on electrode made of catalyst deposited on MWCNTs are more pronounced and occur in narrower potential region. Hydrogen/oxygen evolution occurs at more positive/negative potential and is considerably more intensive on MWCNTs-based electrode compared with corresponding one deposited on Vulcan XC-72.

Analyzing polarization characteristics shown in Fig. 7, it is obvious that considerable improvement of catalytic activity of non-platinum electrode material was achieved by using MWCNTs. The overpotential for hydrogen evolution at reference current density of $60 \mathrm{mAcm}^{-1}$ is $250 \mathrm{mV}$ in the case of CoNi-based catalysts deposited on MWCNTs, while the corresponding value of the electrocatalyst deposited on Vulcan XC-72 is $290 \mathrm{mV}$. Value of the corresponding overpotential for traditional Pt electrocatalyst deposited on Vulcan XC72 is $205 \mathrm{mV}$. Using MWCNTs as a catalyst support decreases the difference between Pt- and CoNi-based catalyst for $50 \%$ and approaches to the activity of the traditional Pt electrocatalyst. The higher activity of CoNi electrodes containing MWCNTs is caused by purely physical factor, mostly of more developed surface area. Carbon nanotubes provide (1) rise of real surface area of the catalyst as a whole, (2) better dispersion of catalyst's particles over the surface, (3) prevent agglomeration of the metallic particles and (4) extra-conductive properties, and (5) better porosity due to geometric nature of nanotubes and morphology of the catalysts as a whole.

\section{Conclusions}

Within this study MWCNTs were produced using electrolysis of molten $\mathrm{LiCl}$ at constant cathode potential. The produced carbonaceous material was studied by means of TEM, SEM, TGA-DTA, and Raman spectroscopy. Further, the produced material was used as support material for nonplatinum electrocatalysts aimed for hydrogen evolution. According to obtained results, we could draw the following conclusions:

1. Instead of constant cell potential electrolysis as reported in the previous works $[20,21]$ or constant applied current $[15,17]$, cathode potential electrolysis used in the present study ensures better conditions for production of MWCNT. The results show that EC4 is a proper material as precursor for the present purpose. The idea of this method was avoiding of cathode blocking, electrode cracking caused by current peaks and improvement of CNTs production.

2. The results obtained by structural study of the carbonaceous material produced by constant overpotential electrolyses in molten $\mathrm{LiCl}$ give sufficient evidence that the observed samples contain more than $80 \%$ MWCNTs. The nanotubes are mostly of curved shape, low crystallinity containing some defects (disordered carbon) and impurities (amorphous carbonaceous products, fullerenes).

3. As a result of the superior physical properties of the MWCNTs such as highly developed surface, extra conductivity, chemical stability, and inter- and trans-particle porosity, they have shown considerably better performance as a catalyst support material related to traditionally most used support material-Vulcan XC-72.

Acknowledgments The authors gratefully acknowledge the financial support from Royal Society of United Kingdom, NATO, and European Commission. Special gratitude from the first author to professor D. J. Fray and Dr. K. Swand for their extensive help and advice throughout the project.

\section{References}

1. Iijima S (1991) Helical microtubules of graphitic carbon. Nature $354: 56-58$

2. Trojanowicz M (2006) Analytical application of carbon nanotubes: a review. Trends in Anal Chem 25:480-489

3. Gooding JJ (2005) Nanostructural electrodes with carbon nanotubes: a review on electrochemistry and application for sensing. Electrochim Acta 50:3049-3060

4. Avouris P (2002) Molecular electronics with carbon nanotubes. Acc Chem Res 35:1026-1034

5. Cooper EB, Manalis SR, Fang H, Dai H, Matsumoto K, Minne SC, Hunt T, Quate CF (1999) Terabit-per-square-inch data storage with the atomic force microscope. Appl Phys Lett 75:3566-3568

6. Roy N, Sengupta R, Bhowmick AK (2012) Modifications of carbon for polymer composites and nanocomposites. Prog Polym Sci 37:781-819

7. Lee YH, An KH, Lim SC, Kim WS, Jeong HJ, Doh C-H, Moon S-I (2002) Application of carbon nanotubes to energy storage devices. New Diam Front Carb Technol 12:209-228

8. Landi BJ, Ganter MJ, Cress CD, DiLeo RA, Raffaelle RP (2009) Carbon nanotubes for lithium ion batteries. Energy Environ Sci 2:638-654

9. Hughes M, Shaffer MSP, Renouf AC, Singh C, Chen GZ, Fray DJ, Windle AH (2002) Electrochemical capacitance of nanocomposite films formed by coating aligned arrays of carbon nanotubes with polypyrrole. Adv Mater 14:382-385

10. Ebbesen TW, Ajayan PM (1992) Large-scale synthesis of carbon nanotubes. Nature 358:220-222

11. Thess A, Lee R, Nikolaev P, Dai H, Petit P, Robert J, Xu C, Lee YH, Kim SG, Rinzler AG, Colbert DT, Scuseria GE, Tomanek D, 
Fischer JE, Smalley RE (1996) Crystalline ropes of metallic carbon nanotubes. Science 273:483-487

12. Kumar M, Ando Y (2010) Chemical vapor deposition of carbon nanotubes: a review on growth mechanism and mass production. $\mathrm{J}$ Nanosci Nanotech 10:3739-3758

13. Hsu WK, Hare JP, Terrones M, Kroto HW, Walton DRM, Harris PJF (1995) Condensed-phase nanotubes. Nature 377:687

14. Hsu WK, Terrones M, Hare JP, Terrones H, Kroto HW, Walton DRM (1996) Electrolytic formation of carbon nanostructures. Chem Phys Lett 262:161-166

15. Novoselova IA, Oliynyk NF, Volkov SV (2007) Electrolytic production of carbon nanotubes in chloride-oxide melts under carbon dioxide pressure. In: Schur DV, Baranowski B, Shpak AP, Skorokhod VV, Kale A, Veziroglu TN, Zaginaichenko SY (eds) Hydrogen materials science and chemistry of carbon nanomaterials. Springer, Berlin, pp 459-465

16. Chen GZ, Fan X, Luget A, Shaffer MSP, Fray DJ, Windle AH (1998) Electrolytic conversion of graphite to carbon nanotubes in fused salts. J Electroanal Chem 446:m1-m6

17. Chen GZ, Kinloch I, Shaffer MSP, Fray DJ, Windle AH (1998) Electrochemical investigation of the formation of carbon nanotubes in molten salts. High Temp Mater Proc 2:459-469

18. Fray DJ (1999) Intercalation from molten salts. High Temp Mater Proc 3:67-76

19. Fray DJ (1999) Intercalation from molten salts. Molt Sal Bull $66: 2-11$

20. Schwandt C, Dimitrov AD, Fray DJ (2010) The preparation of nano-structured carbon materials by electrolysis of molten lithium chloride at graphite electrodes. J Electroanal Chem 647:150-158

21. Dimitrov AD, Chen GZ, Kinloch LA, Fray DJ (2002) A feasibility study of scaling-up the electrolytic production of carbon nanotubes in molten salts. Electrochim Acta 48:91-102

22. Dimitrov AT, Paunovic P, Tomova A, Grozdanov A (2011) Physical characterisation of CNT's produced by electrolysis in molten $\mathrm{LiCl}$. Fray International Symposium, Cancun

23. Maillard F, Simonov PA, Savinova ER (2009) Carbon materials as supports for fuel cell electrocatalysts. In: Serp P, Figueiredo JL (eds) Carbon materials for catalysis. Wiley, New York, pp 429-480

24. Serp P, Corrias M, Kalck P (2003) Carbon nanotubes and nanofibers in catalysis. Appl Catal A: Gen 253:337-338

25. Lee K, Zhang J, Wang H, Wilkinson DP (2006) Progress in the synthesis of carbon nanotube- and nanofibre- supported Pt electrocatalysts for PEM fuel cell catalysis. J Appl Electrochem 36:507522
26. Marsan B, Fradette N, Beaudoin G (1992) Physicochemical and electrochemical properties of $\mathrm{CuCo}_{2} \mathrm{O}_{4}$ electrodes prepared by thermal decomposition for oxygen evolution. J Electrochem Soc 139:1889-1896

27. Da Silva LM, De Faria LA, Boodts JFC (2001) Determination of the morphology factor of oxide layers. Electrochim Acta 47:395403

28. Paunovic P, Radev I, Dimitrov AT, Popovski O, Lefterova E, Slavcheva E, Hadži Jordanov S (2009) New nano-structured and interactive supported composite electrocatalysts for hydrogen evolution with partially replaced platinum loading. Int J Hydr Energy 34:2866-2873

29. Saxby JD, Chatfield SP, Palmisano AJ, Vassallo AM, Wilson MA, Pang LSK (1992) Thermogravimetric analysis of buckminsterfullerene and related materials in air. J Phys Chem 96:17-18

30. Bom D, Andrews R, Jacques D, Anthony J, Chen B, Meier MS, Selegue JP (2002) Thermogravimetric analysis of the oxidation of multiwalled carbon nanotubes: evidence for the role of defect sites in carbon nanotube chemistry. Nano Lett 2:615-619

31. Hiura H, Ebbesen TW, Tanigaki K, Takahashi H (1993) Raman studies of carbon nanotubes. Chem Phys Lett 202:509-512

32. Li W, Zhang H, Wang C, Xu L, Zhu K, Xie S (1997) Raman characterization of aligned carbon nanotubes produced by thermal decomposition of hydrocarbon vapor. Appl Phys Lett 70:26842686

33. Tunistra F, Koenig JL (1970) Raman spectrum of graphite. J Chem Phys 53:1126-1130

34. Pimenta MA, Marucci A, Empedocles SA, Bewendi MG, Hanlon EBV, Rao AM (1998) Raman modes of metallic carbon nanotubes. Phys Rev B 58:R16016-R16019

35. Endo M, Nishimura K, Kim YA, Hakamada K, Matushita T, Dresselhaus MS, Dresselhaus G (1999) Raman spectroscopic characterization of submicron vapor-grown carbon fibers and carbon nanofibers obtained by pyrolyzing hydrocarbons. J Mater Res 14:4474-4477

36. Tan P, Zhang S-L, Yue KT, Huang F, Shi Z, Zhou X, Gu Z (1997) Comparative Raman study of carbon nanotubes prepared by dc arc discharge and catalytic methods. J Ram Spec 28:369-372

37. Paunovic P, Dimitrov AT, Popovski O, Slavkov D, Hadzi Jordanov S (2007) Effect of carbon nanotubes support in improving the performance of mixed electrocatalysts for hydrogen evolution. Mac J Chem Chem Eng 26:87-93

38. Behl WK, Toni JE (1971) Anodic oxidation of cobalt in potassium hydroxide electrolytes. J Electroanal Chem 31:63-75 